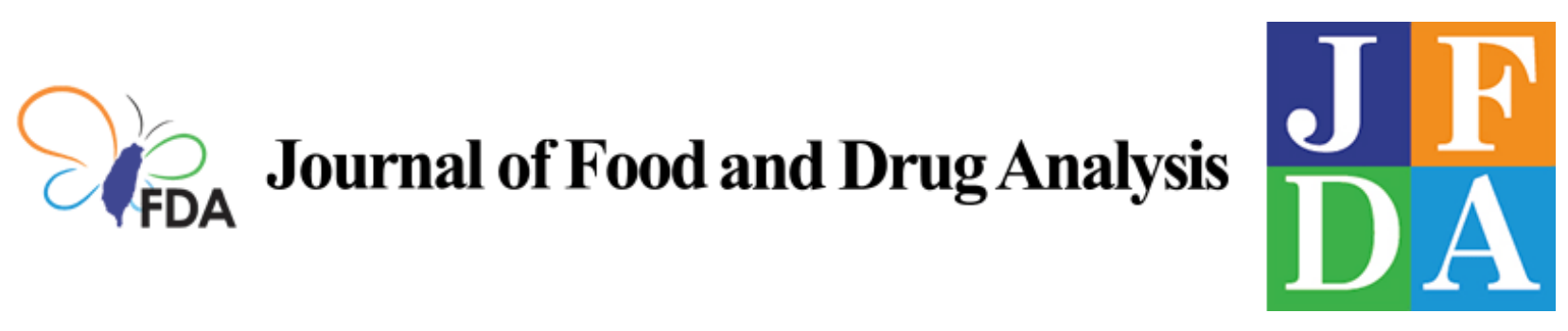

Volume 29 | Issue 2

Article 10

2021

\title{
Characterization of L-theanine in tea extracts and synthetic products using Stable Isotope Ratio Analysis
}

Follow this and additional works at: https://www.jfda-online.com/journal

Part of the Food Science Commons, Medicinal Chemistry and Pharmaceutics Commons, Pharmacology Commons, and the Toxicology Commons

(c) (i) (9)

This work is licensed under a Creative Commons Attribution-Noncommercial-No Derivative Works 4.0 License.

\section{Recommended Citation}

Perini, Matteo; Pianezze, Silvia; Ziller, Luca; and Camin, Federica (2021) "Characterization of L-theanine in tea extracts and synthetic products using Stable Isotope Ratio Analysis," Journal of Food and Drug Analysis: Vol. 29 : Iss. 2 , Article 10.

Available at: https://doi.org/10.38212/2224-6614.3349

This Original Article is brought to you for free and open access by Journal of Food and Drug Analysis. It has been accepted for inclusion in Journal of Food and Drug Analysis by an authorized editor of Journal of Food and Drug Analysis. 


\title{
Characterization of L-theanine in tea extracts and synthetic products using stable isotope ratio analysis
}

\author{
Matteo Perini ${ }^{a}$, Silvia Pianezze ${ }^{\mathrm{a}, \mathrm{d}, *}$, Luca Ziller $^{\mathrm{b}}$, Federica Camin ${ }^{\mathrm{b}, \mathrm{c}}$ \\ a Technology Transfer Centre, Fondazione Edmund Mach (FEM), Via E. Mach 1, 38098, San Michele all'Adige, Italy \\ ${ }^{\mathrm{b}}$ Research and Innovation Centre, Fondazione Edmund Mach (FEM), Via E. Mach 1, 38098, San Michele all'Adige, Italy \\ ${ }^{\mathrm{c}}$ Department of Cellular, Computational and Integrative Biology, University of Trento, Centre Agriculture Food Environment C3A, Via \\ E. Mach 1, 38098, San Michele all'Adige, Italy \\ ${ }^{\mathrm{d}}$ Department of Agricultural and Environmental Sciences, University of Udine, Via Sondrio 2A, 33100, Udine, UD, Italy
}

\begin{abstract}
L-theanine involves a great number of health benefits and dietary supplements containing this molecule are becoming increasingly popular. There is, therefore, a growing need to find ways to discriminate between natural L-theanine extracted from tea leaves and the cheaper, synthetic one obtained using specific bacterial enzymes. A first attempt of stable isotope ratio analysis characterization of the possible synthetic adulterant L-theanine $\left(\delta^{13} \mathrm{C}\right.$ of $-14.3 \pm 1.5 \%$, obtained from vegetable substrates with C4 photosynthetic cycle, and of the more expensive natural L-theanine $\left(\delta^{13} \mathrm{C}\right.$ of $-24.4 \pm 1.3 \%$ ), extracted from Camellia sinensis plants with C3 photosynthetic cycle, is reported here.
\end{abstract}

Keywords: Authentication, Carbon and nitrogen stable isotope ratios, IRMS, L-theanine, Tea

\section{Introduction}

$\mathrm{T}$ he ancient tradition of tea drinking was handed down by the Chinese people, who used the Camellia sinensis plant to produce soups, beverages or infusions well known for their therapeutic properties. Nowadays, we know that the healthy properties of tea are associated, among other compounds, with the presence of a particular amino acid: L-theanine, a chiral species that occurs in nature predominantly in its L(S)enantiomer form [1]. The benefits of L-theanine consumption are countless. This amino acid has been closely associated with relaxation and improved learning abilities [1], as it facilitates the generation of alpha brain waves, associated with a relaxed but alert mental state [2] and promotes the release of GABA, the inhibitory neurotransmitter which regulates brain dopamine and serotonin levels [3,4]. L-theanine has also been recently linked to cancer prevention [5] and to the reduction of the adverse effects of cancer treatment drugs [6]. It has also been associated with blood pressure regulation [5,7], promotion of weight loss and improvement of the immune system [8,9]. Moreover, L-theanine is related to the umami taste in tea $[10,11]$.

Several works have been carried out using Ltheanine as a marker for tea quality and authenticity. Č́žková et al. proposed a method for estimating the content of tea in tea-based products, using markers as theobromine, caffeine, total polyphenols and L-theanine [12]. Moreover, Le Gall et al. used ${ }^{1} \mathrm{H}-\mathrm{NMR}$ to analyze all the components of a single green tea extract, L-theanine included $[12,13]$. They found that, in agreement with previous works $[14,15]$, high levels of L-theanine and other molecules are associated with high quality and therefore highly priced teas [12,13].

As reported by $\mathrm{Mu}$ et al. [16] the L-theanine can be obtained by chemical synthesis, isolation from tea (Camellia sinensis) or, more recently, through

Received 22 January 2021; revised 8 March 2021; accepted 19 March 2021.

Available online 15 June 2021

* Corresponding author: Department of Agricultural and Environmental Sciences, University of Udine, Via Sondrio 2A, 33100, Udine, UD, Italy.

E-mail address: silvia.pianezze@fmach.it (S. Pianezze). 
biological production by the use of specific bacterial enzymes.

In nature, L-theanine is biosynthesized in tea plant roots from glutamic acid and ethylamine, thanks to theanine synthetase. It is then transferred to the trunk and stems through the growing shoots and leaves, and it accumulates in developing leaves [1]. Several studies confirm that L-theanine constitutes, on average, only $1-3 \%$ of the weight of dry tea leaves [17-19]. It is also necessary to consider that the extraction of high purity L-theanine from tea plants is challenging, because of the presence of high concentrations of other soluble substances in tea, such as caffeine and polyphenols [20]. Therefore, it is clear that producing supplements from tea extract entails high costs and time-consuming manufacturing procedures.

The chemical synthesis of theanine involves the reaction of $\gamma$-benzyl glutamate in the presence of trityl chloride and ethylamine and an initial dehydration of L-glutamic acid to L-pyrrolidone carboxylic acid, followed by ring opening in the presence of ethylamine to yield theanine [1]. Consumers are reluctant to accept the chemical synthesis of theanine, as it is not allowed for use in the food industry and, generally, the reaction does not produce only the L(S)- form, but a racemic mixture [16,21,22].

Starting from L-glutamine or L-glutamic acid and ethylamine, the alternative biological enzymatic synthesis leads to the formation of L-theanine, thanks to bacterial enzymes such as glutaminase, glutamine synthetase and $\gamma$-glutamyltranspeptidase [1]. Four kinds of bacterial enzymes display potential as ideal biocatalysts, namely, Lglutamine synthetase (GS), $\gamma$-glutamylmethylamide synthetase (GMAS), $\gamma$-glutamyltranspeptidase (GGT), and L-glutaminase [16]. L-glutamine is industrially produced from L-glutamic acid that, in turn, is produced through the enzymatic fermentation of glucose [23]. Both chemical and enzymatic synthesis (producing synthetic L-theanine) offer a simple, convenient and cost-effective alternative to L-theanine extraction from tea leaves, but enzymes are stereospecific and offer the advantage of producing the naturally occurring L-(S) enantiomer of theanine. Therefore, unlike chemical synthesis, the enzymatic one will not lead to the formation of a racemic mixture, solving this drawback.

Due to the growing demand for L-theanine, the industrial production of this food supplement has high market value and carries economic importance [24]. Thus, to prevent economic frauds, it is necessary to develop a method to determine whether a declared natural L-theanine product is true to its description or an intentional mislabel is taking place. To the best of our knowledge, a method to authenticate L-theanine samples has not been developed yet. On the other hand, stable isotope ratio analysis, particularly of carbon $\left({ }^{13} \mathrm{C} /{ }^{12} \mathrm{C}\right)$, has been widely applied to food supplements [25] to assess their authenticity. Therefore, the aim of this study is to check whether carbon stable isotope ratio analysis can discriminate between L-theanine extracted from tea and synthetic L-theanine produced through chemical or enzymatic synthesis. 30 samples of tea were processed to obtain an L-theanine-enriched extract through preparative High Performance Liquid Chromatography (HPLC). Furthermore, 10 synthetic samples and 28 L-theanine commercial samples were considered. Extracts and pure L-theanine samples were subjected to the analysis not only of ${ }^{13} \mathrm{C} /{ }^{12} \mathrm{C}$ but also of ${ }^{15} \mathrm{~N} /{ }^{14} \mathrm{~N}$, measured in the same analytical run, to investigate the further potentiality of this isotopic marker in distinguishing the two production sources.

\section{Materials and method}

\subsection{Sampling}

30 samples of different types of tea, 10 samples of pure synthetic L-theanine with purity $>98 \%$ and 28 commercial samples containing different concentrations of L-theanine were collected. White, black and green tea samples were purchased from Peter's Tea House Trading SRL, which certified the origin of the product, taking care to choose different tea varieties with different geographical origins. Synthetic samples were purchased from different suppliers. Commercial samples were purchased on the market in different countries. All information about the samples are reported in Table $1 S$ of the supplementary material.

\subsection{Extraction of tea samples and commercial products}

In order to extract L-theanine, 3.0-3.5 $\mathrm{g}$ of dry tea leaves of each sample were ground to a powder. 40 $\mathrm{mL}$ of deionized cold water were then added to the samples, which were subsequently left into a sonic bath for $60 \mathrm{~min}$. The solution was purified through a paper filter (Whatman cellulose filters for technical use, Grade 0860 1/2). A final passage through a 0.45 $\mu \mathrm{m}$ filter readied the sample for analysis. The liquid extract obtained was then purified through preparative HPLC.

In order to analyze commercial samples containing L-theanine, all available in powder form, 
solutions of $10 \mathrm{mg} / \mathrm{mL}$ of commercial samples in deionized water were prepared. A filtration through a $0.45 \mu \mathrm{m}$ filter was carried out to get the sample ready to be purified through preparative HPLC.

\subsection{HPLC separation}

Preparative HPLC separation was performed by injecting $2 \mathrm{~mL}$ of the above mentioned solutions (Section 2.2) into a Luna Omega $(21.2 \times 250 \mathrm{~mm}, 5$ $\mu \mathrm{m})$ PS C-18 HPLC Column. Elution was performed using Shimadzu LC-20AP pumps. The isocratic run was carried out by using MILLIQ water at a flow rate of $10 \mathrm{~mL}$ per minute. The total analysis time was $20 \mathrm{~min}$. L-theanine was detected by absorbance at $195 \mathrm{~nm}$ and was collected between 10 and $11 \mathrm{~min}$. The samples were then frozen and lyophilized.

Due to the really complex matrix of tea, it was not possible to extract pure L-theanine from tea samples, but an extract with a concentration of L-theanine not lower than $30 \% \mathrm{w} / \mathrm{w}$ was obtained (Ltheanine-enriched tea extract). For the quantification of L-theanine in the extract obtained, the method reported by Tadesse et al. was followed without changes [26].

\subsection{Stable isotope ratio analysis}

The stable isotope ratios of carbon and nitrogen were measured in both L-theanine synthetic and Ltheanine-enriched tea and commercial samples extracts.

The ${ }^{13} \mathrm{C} /{ }^{12} \mathrm{C}$ and ${ }^{15} \mathrm{~N} /{ }^{14} \mathrm{~N}$ ratios were measured in duplicate during a single run $(0.2 \mathrm{mg}$ for each sample) using an isotope ratio mass spectrometer (IRMS) (Finnigan DELTA XP, Thermo Scientific, Bremen, Germany) following total combustion in an elemental analyser (EA) (Flash EA 1112, Thermo Scientific, Bremen, Germany). According to the IUPAC protocol, the values are denoted as deltas in relation to the international V-PDB (Vienna-Pee Dee Belemnite) for $\delta^{13} \mathrm{C}$, Air for $\delta^{15} \mathrm{~N}$ according to the following general equation [27]:

$\delta$ i $\mathrm{E}=(\mathrm{i}$ RSA - i RREF $) /$ i RREF

where $i$ is the mass number of the heavier isotope of element $\mathrm{E}, \mathrm{RSA}$ is the respective isotope ratio of the sample and RREF is the relevant internationally recognised reference material. The delta values were multiplied by 1000 and expressed in units "per mil" (\%). The isotopic values were calculated against in-house working standards, which were themselves calibrated against international reference materials: fuel oil NBS-22 with $\delta^{13} \mathrm{C}=$
$-30.03 \%$, sucrose IAEA-CH-6 with $\delta^{13} \mathrm{C}=-10.45 \%$ o (IAEA-International Atomic Energy Agency, Vienna, Austria), and L-glutamic acid USGS 40 with $\delta^{13} \mathrm{C}=-26.39 \%$ and $\delta^{15} \mathrm{~N}=-4.52 \%$ (U.S. Geological Survey, Reston, VA, USA) for ${ }^{13} \mathrm{Cl}^{12} \mathrm{C}$ and ${ }^{15} \mathrm{~N} /{ }^{14} \mathrm{~N}$ and potassium nitrate IAEA-NO3 $\left(\delta^{15} \mathrm{~N}=\right.$ $+4.7 \%$ ) from IAEA for ${ }^{15} \mathrm{~N} /{ }^{14} \mathrm{~N}$. The uncertainty of the method (calculated as one standard deviation when analysing the same sample at least ten times under reproducible conditions) was $0.1 \%$ for $\delta^{13} \mathrm{C}$ and $0.2 \%$ for $\delta^{15} \mathrm{~N}$ values.

\subsection{Statistical analysis}

The Wilcoxon test was applied to compare the two unpaired populations using RStudio version 1.2.5033 (2019).

\section{Results and discussion}

\subsection{Validation of the method}

In order to test the repeatability of the method, one sample of tea was processed through HPLC 10 times to get the L-theanine-enriched tea extract. As reported in Table 1, the standard deviations of repeatability were $0.2 \%$ for $\delta^{13} \mathrm{C}$ and $0.2 \%$ for $\delta^{15} \mathrm{~N}$.

Furthermore, to prove the absence of fractionation processes during the extraction procedure, a standard sample of L-theanine was measured both before and after HPLC extraction. Differences between the standard sample before and after HPLC extraction of $0.3 \%$ for $\delta^{13} \mathrm{C}$ and of $0.0 \%$ for $\delta^{15} \mathrm{~N}$ were obtained (Table 2).

Considering the obtained SD of repeatability, the difference between isotopic values before and after the extraction is not significant and we could assume that no fractionation processes occurred during the sample processing.

Table 1. Repeatability of the method for carbon and nitrogen stable isotopic ratio of L-theanine-enriched tea extract.

\begin{tabular}{lll}
\hline & $\begin{array}{l}\delta^{13} \mathrm{C} \\
(\% 0, \text { vs V-PDB) }\end{array}$ & $\begin{array}{l}\delta^{15} \mathrm{~N} \\
(\%, \text { vs AIR) }\end{array}$ \\
\hline $\mathbf{1}$ & -25.5 & 5.5 \\
$\mathbf{2}$ & -25.5 & 5.5 \\
$\mathbf{3}$ & -25.3 & 5.4 \\
$\mathbf{4}$ & -25.0 & 5.4 \\
$\mathbf{5}$ & -25.3 & 6.0 \\
$\mathbf{6}$ & -25.4 & 5.4 \\
$\mathbf{7}$ & -25.2 & 5.1 \\
$\mathbf{8}$ & -25.2 & 5.3 \\
$\mathbf{9}$ & -25.6 & 5.6 \\
$\mathbf{1 0}$ & -25.4 & 5.4 \\
\hline Mean & -25.3 & 5.5 \\
SD & 0.2 & 0.2 \\
\hline
\end{tabular}


Table 2. Test to prove the absence of isotopic fractionation during the HPLC extraction.

\begin{tabular}{lll}
\hline & $\begin{array}{l}\delta^{13} \mathrm{C} \\
(\%, \text { vs V-PDB) }\end{array}$ & $\begin{array}{l}\delta^{15} \mathrm{~N} \\
(\%, \text { vs } \text { AIR })\end{array}$ \\
\hline pre-HPLC extraction & -14.5 & -3.3 \\
post-HPLC extraction & -14.8 & -3.3 \\
\hline$\Delta \delta \% 0$ & 0.3 & 0.0 \\
\hline
\end{tabular}

\subsection{Differences between $\delta^{13} \mathrm{C}$ and $\delta^{15} \mathrm{~N}$ in}

$L$-theanine-enriched tea extracts and synthetic L-theanine

As represented in Fig. 1, L-theanine-enriched tea extracts and synthetic L-theanine samples (regardless of the method through which they were obtained, whether chemical or enzymatic) showed different ranges of $\delta^{13} \mathrm{C}$ and $\delta^{15} \mathrm{~N}$. The Wilcoxon test for unpaired samples was applied, confirming a significant difference between natural and synthetic samples $\left(\delta^{15} \mathrm{~N} p<0.001\right.$ and $\left.\delta^{13} \mathrm{C} p<0.001\right)$.

\subsection{1. $\delta^{13} \mathrm{C}$ of L-theanine}

In this first explorative study, the L-theanineenriched tea extracts (samples 1-30, Table 1S) showed a mean $\delta^{13} \mathrm{C}$ value of $-24.4 \pm 1.3 \%$ (Fig. 1). This behaviour is in line with the botanical origin of the matrices. Indeed, Camellia sinensis is an evergreen shrub belonging to the group of C3 photosynthetic cycle plants that show a typical stable isotopic range of $\delta^{13} \mathrm{C}$ of between -30 and $-23 \%$ [28-30]. As already mentioned, in the tea plant, L- theanine is biosynthesized from glutamic acid and ethylamine by the theanine synthetase enzyme [31].

Unlike natural L-theanine, the L-theanine samples analysed in this study and produced through synthetic processes (samples 31-40, Table 1S) showed a mean $\delta^{13} \mathrm{C}$ of $-14.3 \pm 1.5 \%$ (Fig. 1 ). As previously mentioned, the industrial synthesis of Ltheanine consists in a chemical or an enzymatic process starting from L-glutamine or glutamic acid and ethylamine. Commercial glucose is normally produced via the enzymatic hydrolysis of starch [32] and corn is the main crop used as a source of starch [33]. As reported by O'Leary, the normal range of a plant with a $\mathrm{C} 4$ photosynthetic cycle like cane or maize is between -10 and $-16 \%$ [34]. Glucose obtained from C4 plants was used in the production of L-glutamic acid and therefore of L-theanine. Indeed, the mean $\delta^{13} \mathrm{C}$ of synthetically produced L-theanine samples is $-14.0 \%$ (values ranging from -10.9 and $-15.9 \%$ ), which perfectly fits a C4 plant profile.

\subsection{2. $\delta^{15} \mathrm{~N}$ of L-theanine}

In addition to the natural composition of the soil, one of the main factor of influence on the nitrogen isotopic ratio in cultivated lands is the fertilization practice used. Synthetic fertilizers produced via Haber process have values ranging from -4 to $+4 \%$, while organic fertilizers are characterized by values ranging from +0.6 to $+36.7 \%$ o [35]. Also the environmental conditions influence the nitrogen isotopic ratio, high aridity being associated with higher $\delta^{15} \mathrm{~N}$. Indeed, it has been reported that warm and

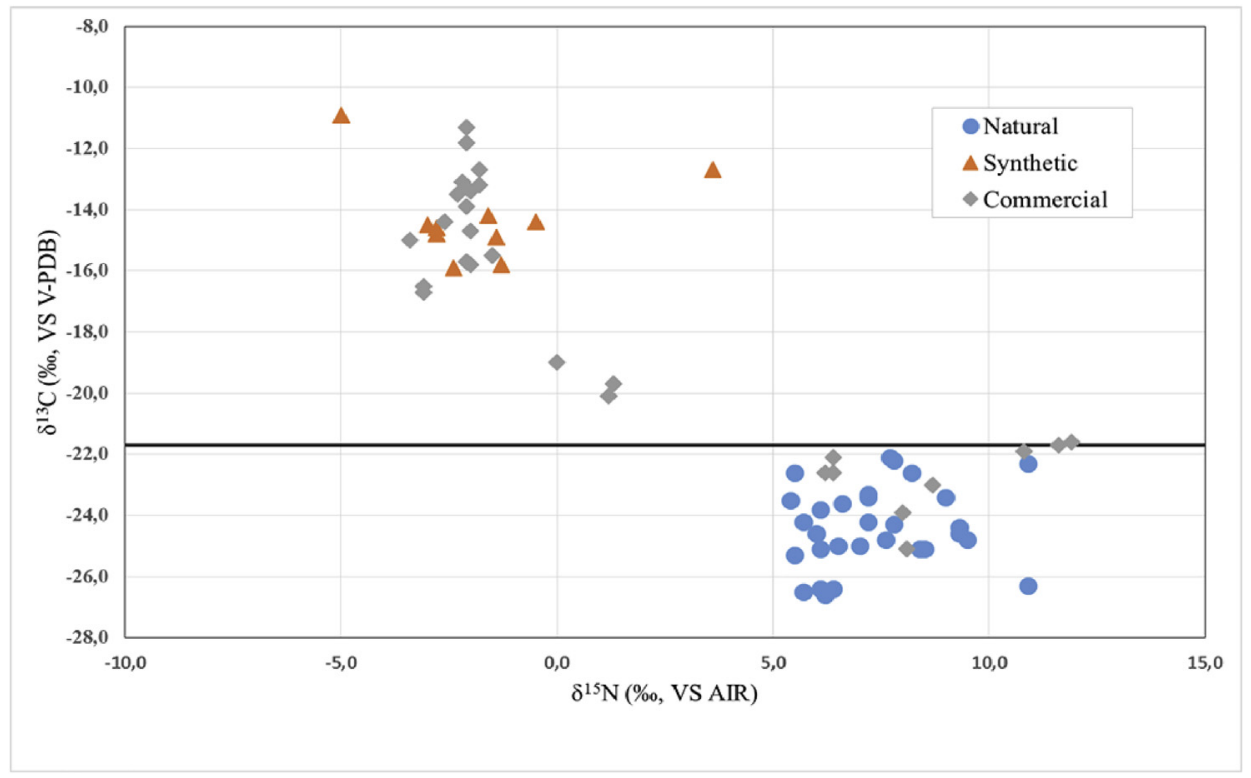

Fig. 1. Plot of $\delta^{13} \mathrm{C}$ vs $\delta^{15} \mathrm{~N}$ of natural enriched tea extract, commercial and synthetic L-theanine samples. The dark line defines the $95 \%$ threshold limit for authentic L-theanine-enriched tea extract. 
arid regions can result in plant food commodities with relatively high nitrogen isotopic ratios [36]. The $\delta^{15} \mathrm{~N}$ values of L-theanine-enriched tea extract show, in the samples of this study, a mean $\delta^{15} \mathrm{~N}$ of $7.4 \pm$ $1.6 \%$ and vary from +5.4 to $+10.9 \%$. These values, higher than those found for synthetic samples (mean $\delta^{15} \mathrm{~N}$ of $-2.0 \pm 1.5 \%$, from -3.0 to $+3.6 \%$ ), are difficult to interpret as cultivation practices change depending on the site where the tea plants grow. $\delta^{15} \mathrm{~N}$ cannot be considered as the only parameter in the evaluation of the source of L-theanine, but it seems to add further information to that provided by the carbon isotope ratio. In synthetic L-theanine, the lower $\delta^{15} \mathrm{~N}$ values obtained are probably due to the addition of ammonium sulphate $\left(\delta^{15} \mathrm{~N}=-3.1 \pm\right.$ 0.66) [37] to the yeast broth as a source of nitrogen $[28,29]$.

\subsection{Authenticity limits}

Considering a confidence level of $95 \%$ (mean value $\pm t$-student $x$ std. dev) and on the basis of the authentic samples analysed in this study, a first $\delta^{13} \mathrm{C}$ authenticity threshold value of $-21.7 \%$ o can be proposed for L-theanine-enriched tea extract. Higher, i.e. less negative values can be associated with the addition of synthetically produced L-theanine to natural products. Nevertheless, for legal purposes, the need to more clearly define the range of variability of the natural product by setting up a specific database remains. This is the only way to propose a more reliable limit.

In order to assume the percentage of synthetic Ltheanine added to the natural enriched tea extract of the amino acid, a graph was created on the basis of the mean and the standard deviation (multiplied by $\mathrm{t}$-student) of $\delta^{13} \mathrm{C}$ of the two groups, and increasing the percentage addition of synthetic L-theanine from $0 \%$ to $100 \%$ (Fig. 2). The mean values of the mixture (blue spots) were calculated as the sum of the mean values for the two groups, multiplied by the percentage of contribution to the mixture, whereas the standard deviation was the sum of the standard deviation of the two groups multiplied by the percentage of contribution, according to the law of error propagation in the case of the sum of two or more variables (Fig. 2). The validity of the graph was confirmed by analysing five adulterated mixtures of L-theanine prepared by adding a growing \% (from $0 \%$ to $100 \%)$ of synthetic L-theanine $\left(\delta^{13} \mathrm{C}=\right.$ $-12.7 \%$ ) to a natural enriched tea extract $\left(\delta^{13} \mathrm{C}=\right.$ $-26.4 \%$ ). The values of these five samples are shown as orange spots in Fig. 2.

From this graph and on the basis of the $\delta^{13} \mathrm{C}$ values of the commercial samples, it could be possible to formulate a first interpretation about the authenticity of a L-theanine natural tea extract.

As for $\delta^{15} \mathrm{~N}$, we did not define an authenticity limit, due to the variability of this parameter linked to fertilization practices and geographical origins.

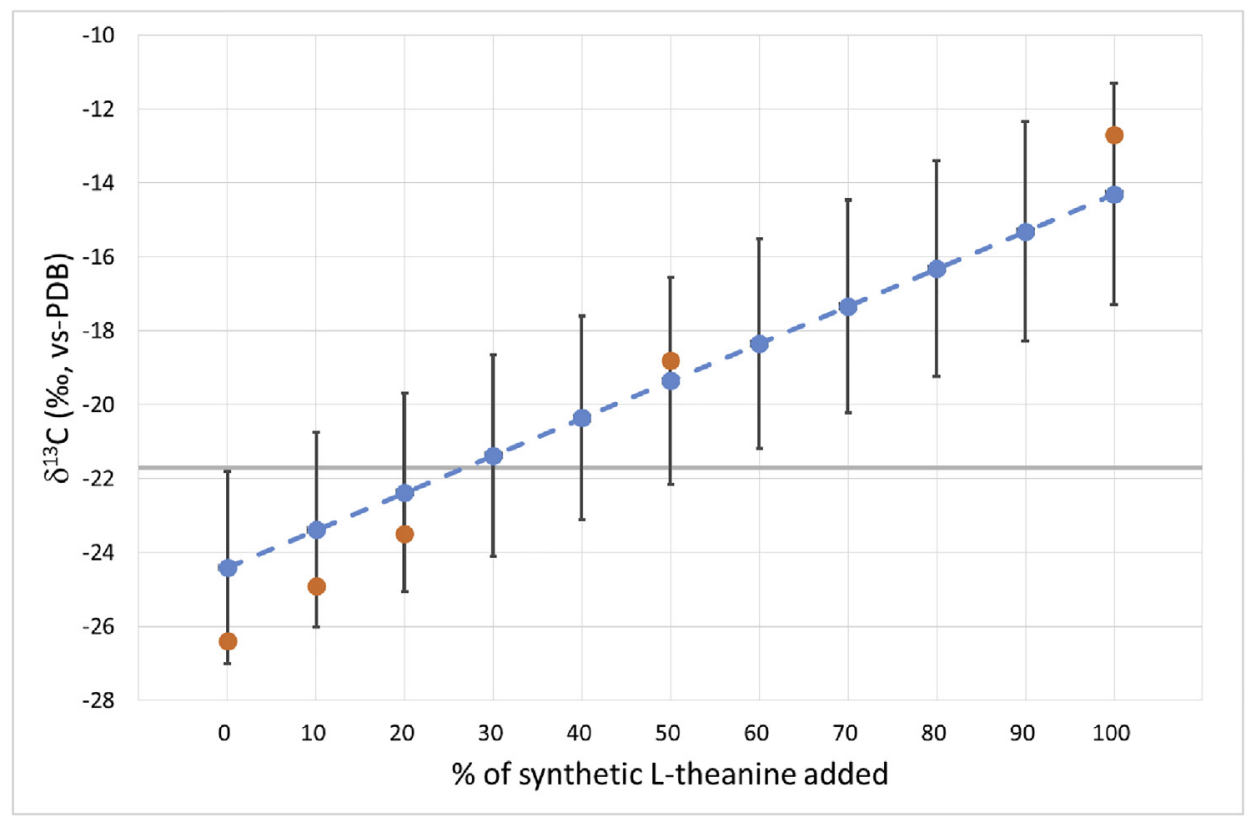

Fig. 2. Variations in the $\delta^{13} \mathrm{C}$ values of natural L-theanine-enriched tea extract with the addition of synthetic L-theanine. The grey line defines the 95\% threshold limit for authentic L-theanine-enriched tea extract. 
$\delta^{15} \mathrm{~N}$ can be taken into account to confirm the interpretation drafted on the basis of $\delta^{13} \mathrm{C}$.

\subsection{Characterization of the commercial samples}

Commercial samples analysed in this study showed $\delta^{13} \mathrm{C}$ values of L-theanine contained ranging from -25.1 to $-11.3 \%$ and $\delta^{15} \mathrm{~N}$ from +11.9 to $-3.4 \%$ (Fig. 1). The results, together with the declared content of L-theanine and its attempt at classification as natural or synthetic are reported in Table 1S. The classification was made on the basis of the $\delta^{13} \mathrm{C}$ values of the sample and the authenticity limit proposed. Although all the commercial samples were labelled as containing natural L-theanine from tea leaves, only five of them had $\delta^{13} \mathrm{C}$ values within the range of authenticity proposed in this study. For four other samples (41, 46, 65 and 66), it was not possible to give an opinion, as they are too close to the proposed limit. As for the values that were much less negative than the proposed limit, they can be explained by the addition of different percentages of synthetically produced L-theanine to a natural tea product, or by its entire replacement.

For all the samples classified as adulterated on the basis of their $\delta^{13} \mathrm{C}$ values, the $\delta^{15} \mathrm{~N}$ values were also lower than the minimum value found in this study $(+5.4 \%$ ) .

The high number of anomalous samples found in this limited market investigation demonstrates the need for a screening method that can combat the painstaking practice of replacing a natural product with its synthetic counterpart.

\section{Conclusion}

An analytical method to discriminate between natural enriched L-theanine extract from tea and synthetic L-theanine, using $\delta^{13} \mathrm{C}$ and $\delta^{15} \mathrm{~N}$ through IRMS, was proposed. Synthetic L-theanine showed typical $\delta^{13} \mathrm{C}$ values, due to the photosynthetic cycle of the matrixes used in the process of production (C4 plant instead of C3 plant, e.g. Camellia sinensis, from which natural L-theanine derives). Moreover, the $\delta^{15} \mathrm{~N}$ values confirmed this separation. The $\delta^{13} \mathrm{C}$ value of $-21.7 \%$ o was defined as a first authenticity threshold for natural L-theanine from tea on the basis of the authentic samples analysed in this study. To confirm the $\delta^{13} \mathrm{C}$ limit reported in this work, further samples should be analysed in order to widen the database. Based on these first results, it is believed that the method will make it possible to verify the authenticity of commercial L-theanine and to determine the amount of cheap synthetic Ltheanine added fraudulently.

\section{Conflict of interest}

The authors declare that they have no known competing financial interests or personal relationships that could have appeared to influence the work reported in this paper.

\section{Acknowledgments}

The authors are grateful to Dr. Stefan Siebrecht for contributing to sampling.

\section{Appendix A. Supplementary material}

Table 1S. Description of the natural enriched tea extract, synthetic and commercial L-theanine samples.

\begin{tabular}{llllll}
\hline SAMPLE & Product & Tea Type & Origin Country & $\delta^{15} \mathrm{~N}_{\%}$ (VS AIR) & $\delta^{13} \mathrm{C} \%$ (VS V-PDB) \\
\hline 1 & Natural & WHITE & CHINA & 7.6 & -24.8 \\
2 & Natural & GREEN & INDONESIA & 7.8 & -22.2 \\
3 & Natural & GREEN & JAPAN & 8.5 & -25.1 \\
4 & Natural & GREEN & SRI LANKA & 7.2 & -23.3 \\
5 & Natural & GREEN & INDIA & 10.9 & -22.3 \\
6 & Natural & GREEN & JAPAN & 10.9 & -26.3 \\
7 & Natural & GREEN & JAPAN & 6.4 & -26.4 \\
8 & Natural & GREEN & CHINA & 6.6 & -23.6 \\
9 & Natural & GREEN & CHINA & 5.5 & -22.6 \\
10 & Natural & GREEN & INDIA & 5.7 & -24.2 \\
11 & Natural & GREEN & JAPAN & 6.5 & -25.0 \\
12 & Natural & GREEN & CHINA & 6.1 & -25.1 \\
13 & Natural & GREEN & CHINA & 7.8 & -24.3 \\
14 & Natural & GREEN & INDIA & 5.4 & -23.5 \\
15 & Natural & GREEN & JAPAN & 7.0 & -25.0 \\
16 & Natural & GREEN & TANZANIA & 9.0 & -23.4 \\
17 & Natural & GREEN & KOREA & 9.3 & -24.6 \\
18 & Natural & GREEN & JAPAN & 9.5 & -24.8 \\
19 & Natural & - & CHINA & 5.5 & -25.3
\end{tabular}


Table 1S. (continued)

\begin{tabular}{|c|c|c|c|c|c|c|c|}
\hline SAMPLE & Product & Tea Type & & Origin Country & $\delta^{15} \mathrm{~N} \%$ & & $\delta^{13} \mathrm{C} \%$ (VS V-PDB) \\
\hline$\overline{20}$ & Natural & BLACK & & INDIA & 8.2 & & -22.6 \\
\hline 21 & Natural & BLACK & & CHINA & 9.3 & & -24.4 \\
\hline 22 & Natural & - & & CHINA & 7.2 & & -24.2 \\
\hline 23 & Natural & - & & CHINA & 6.1 & & -26.4 \\
\hline 24 & Natural & - & & CHINA & 5.7 & & -26.5 \\
\hline 25 & Natural & - & & CHINA & 6.2 & & -26.6 \\
\hline 26 & Natural & BLACK & & INDIA & 7.7 & & -22.1 \\
\hline 27 & Natural & BLACK & & CHINA & 7.2 & & -23.4 \\
\hline 28 & Natural & GREEN & & INDIA & 6.1 & & -23.8 \\
\hline 29 & Natural & GREEN & & INDIA & 8.4 & & -25.1 \\
\hline 30 & Natural & GREEN & & INDIA & 6.0 & & -24.6 \\
\hline & & Producer & & L-theanine content $(\%)$ & & & \\
\hline$\overline{31}$ & Synthetic & TCI DEUTSCHLAND GN & $\overline{\mathrm{BH}}$ & 98 & 3.6 & & -12.7 \\
\hline 32 & Synthetic & THERMO FISCHER & & 98 & -2.8 & & -14.6 \\
\hline 33 & Synthetic & abcamBiochemicals & & 98 & -0.5 & & -14.4 \\
\hline 34 & Synthetic & SIGMA-ALDRICH & & 98 & -3.0 & & -14.5 \\
\hline 35 & Synthetic & FOCUS SUPPLEMENT & & 98 & -2.4 & & -15.9 \\
\hline 36 & Synthetic & - & & 98 & -1.6 & & -14.2 \\
\hline 37 & Synthetic & - & & 98 & -1.4 & & -14.9 \\
\hline 38 & Synthetic & - & & 98 & -1.3 & & -15.8 \\
\hline 39 & Synthetic & - & & 98 & -2.8 & & -14.8 \\
\hline 40 & Synthetic & - & & 98 & -5.0 & & -10.9 \\
\hline & & Purchasing Country & $\overline{\text { Dec }}$ & ed L-theanine content ( $\%)$ & & & Classification \\
\hline$\overline{41}$ & Commercial & GERMANY & 10 & & 11.9 & -21.6 & Not classified \\
\hline 42 & Commercial & GERMANY & 20 & & 6.2 & -22.6 & Natural \\
\hline 43 & Commercial & GERMANY & 30 & & 6.4 & -22.6 & Natural \\
\hline 44 & Commercial & UK & 24 & & -3.1 & -16.5 & Adulterated \\
\hline 45 & Commercial & UK & 60 & & -2.0 & -14.7 & Adulterated \\
\hline 46 & Commercial & GERMANY & 10 & & 11.6 & -21.7 & Not classified \\
\hline 47 & Commercial & GERMANY & 40 & & 0.0 & -19.0 & Adulterated \\
\hline 48 & Commercial & GERMANY & 20 & & 1.2 & -20.1 & Adulterated \\
\hline 49 & Commercial & GERMANY & - & & 1.3 & -19.7 & Adulterated \\
\hline 50 & Commercial & GERMANY & - & & -2.1 & -15.7 & Adulterated \\
\hline 51 & Commercial & FRANCE & 14 & & -2.1 & -13.9 & Adulterated \\
\hline 52 & Commercial & FRANCE & 14 & & -1.8 & -12.7 & Adulterated \\
\hline 53 & Commercial & GERMANY & 49 & & -1.8 & -13.2 & Adulterated \\
\hline 54 & Commercial & USA & 40 & & -2.0 & -15.8 & Adulterated \\
\hline 55 & Commercial & UK & 100 & & -2.1 & -11.8 & Adulterated \\
\hline 56 & Commercial & GERMANY & 73 & & -1.5 & -15.5 & Adulterated \\
\hline 57 & Commercial & GERMANY & 49 & & -2.3 & -13.5 & Adulterated \\
\hline 58 & Commercial & GERMANY & 83 & & -2.1 & -11.3 & Adulterated \\
\hline 59 & Commercial & GERMANY & 49 & & -2.2 & -13.1 & Adulterated \\
\hline 60 & Commercial & GERMANY & 49 & & -2.0 & -13.4 & Adulterated \\
\hline 61 & Commercial & UK & 100 & & -3.1 & -16.7 & Adulterated \\
\hline 62 & Commercial & UK & - & & -2.6 & -14.4 & Adulterated \\
\hline 63 & Commercial & FRANCE & - & & -3.4 & -15.0 & Adulterated \\
\hline 64 & Commercial & GERMANY & 30 & & 8.7 & -23.0 & Natural \\
\hline 65 & Commercial & GERMANY & 10 & & 10.8 & -21.9 & Not classified \\
\hline 66 & Commercial & GERMANY & 20 & & 6.4 & -22.1 & Not classified \\
\hline 67 & Commercial & - & - & & 8.1 & -25.1 & Natural \\
\hline 68 & Commercial & ITALY & - & & 8.0 & -23.9 & Natural \\
\hline
\end{tabular}

\section{References}

[1] Vuong QV, Bowyer MC, Roach PD. L-Theanine: properties, synthesis and isolation from tea. J Sci Food Agric 2011;91: 1931-9.

[2] Cooper R, Morré DJ, Morré DM. Medicinal benefits of green tea: Part I. Review of noncancer health benefits. J Alternative Compl Med 2005;11:521-8.
[3] Mason R. $200 \mathrm{mg}$ of Zen: L-theanine Boosts alpha waves, promotes alert relaxation. Focus Alternative Compl Ther 2001;7:91-5.

[4] Juneja LR, Shamtsyan MM. Enzymaticaly fermented amino acid theanine. J Biotechnol 2007;131:S62.

[5] Liu Q, Duan H, Luan J, Yagasaki K, Zhang G. Effects of theanine on growth of human lung cancer and leukemia cells as well as migration and invasion of human lung cancer cells. Cytotechnology 2009;59:211-7. 
[6] Sugiyama T, Sadzuka Y. Theanine, a specific glutamate derivative in green tea, reduces the adverse reactions of doxorubicin by changing the glutathione level. Cancer Lett 2004;212:177-84.

[7] Juneja L. L-theanine - a unique amino acid of green tea and its relaxation effect in humans. Trends Food Sci Technol 1999;10:199-204.

[8] Farooqui T, Farooqui AA. Neuroprotective effects of phytochemicals in neurological disorders. John Wiley \& Sons; 2017.

[9] Takagi Y, Kurihara S, Higashi N, Morikawa S, Kase T, Maeda A, et al. Combined administration of L-cystine and L-theanine enhances immune functions and protects against influenza virus infection in aged mice. J Vet Med Sci 2010;72: 157-65.

[10] Kaneko S, Kumazawa K, Masuda H, Henze A, Hofmann T. Molecular and sensory studies on the umami taste of Japanese green tea. J Agric Food Chem 2006;54:2688-94.

[11] Ekborg-Ott KH, Helen Ekborg-Ott K, Taylor A, Armstrong DW. Varietal differences in the total and enantiomeric composition of theanine in tea. J Agric Food Chem 1997;45: 353-63.

[12] Č́ízová H, Voldřich M, Mlejnecká J, Kvasnička F. Authenticity evaluation of tea-based products. Czech J Food Sci 2008;26:259-67.

[13] Le Gall G, Colquhoun IJ, Defernez M. Metabolite profiling using (1)H NMR spectroscopy for quality assessment of green tea, Camellia sinensis (L.). J Agric Food Chem 2004;52: 692-700.

[14] Horie H, Kohata K. Application of capillary electrophoresis to tea quality estimation. J Chromatogr A 1998;802:219-23.

[15] Aucamp JP, Hara Y, Apostolides Z. Simultaneous analysis of tea catechins, caffeine, gallic acid, theanine and ascorbic acid by micellar electrokinetic capillary chromatography. J Chromatogr A 2000;876:235-42.

[16] Mu W, Zhang T, Jiang B. An overview of biological production of L-theanine. Biotechnol Adv 2015;33:335-42.

[17] Zhang Z, Wan X, Li D. Chemistry and biological properties of theanine. Nutraceutical Science and Technology; 2008. p. 255-74.

[18] Harbowy ME, Balentine DA, Davies AP, Cai Y. Tea chemistry. Crit Rev Plant Sci 1997;16:415-80. http://dx.doi.org/ 10.1080/07352689709701956.

[19] Vuong QV, Stathopoulos CE, Golding JB, Nguyen MH, Roach PD. Optimum conditions for the water extraction of Ltheanine from green tea. J Separ Sci 2011;34:2468-74.

[20] Preedy VR. Caffeine: chemistry, analysis, function and effects. Royal Society of Chemistry; 2015.

[21] Gu H, Jiang Y, Wang J. A practical synthesis of Ethyl Lglutamine. ChemInform 2004;35. http://dx.doi.org/10.1002/ chin.200435184.

[22] Zhang ZZ, Yan SH, Da Xiang L, Ling TJ, Meurens M, Larondelle Y. Chemical synthesis and the stability of theanine. Adv Mater Res 2011;396-398:1273-7. http://dx.doi.org/ 10.4028/www.scientific.net/amr.396-398.1273.

[23] Shyamkumar R, Moorthy IMG, Ponmurugan K, Baskar R. Production of L-glutamic acid with corynebacterium glutamicum (NCIM 2168) and Pseudomonas reptilivora (NCIM 2598): a study on immobilization and reusability. Avicenna J Med Biotechnol (AJMB) 2014;6:163-8.

[24] Adhikary R, Mandal V. L -theanine: a potential multifaceted natural bioactive amide as health supplement. Asian Pac J Trop Biomed 2017;7:842-8. http://dx.doi.org/10.1016/j.apjtb. 2017.08.005.

[25] Perini M, Carbone G, Camin F. Stable isotope ratio analysis for authentication of red yeast rice. Talanta 2017;174:228-33.

[26] Tadesse A, Hymete A, Bekhit AA, Mohammed SF. Quantification of total polyphenols, catechin, caffeine, L-theanine determination of antioxidant activity and effect on antileishmanial drugs of ethiopian tea leaves extracts. Pharmacogn Res 2015;7:S7-14.

[27] Coplen TB. Guidelines and recommended terms for expression of stable-isotope-ratio and gas-ratio measurement results. Rapid Commun Mass Spectrom 2011;25: 2538-60.

[28] O'Leary MH. Carbon isotope fractionation in planta. Phytochem 1981;20:553-67.

[29] Schmidt HL, Winkler FJ. Food quality control and studies on human nutrition by mass pectrometric and nuclear magnetic resonance isotope ratio determination. Ber Deutsch Bot Ges 1979;92:185-91.

[30] Camin F, Perini M, Colombari G, Bontempo L, Versini G. Influence of dietary composition on the carbon, nitrogen, oxygen and hydrogen stable isotope ratios of milk. Rapid Commun Mass Spectrom 2008;22:1690-6.

[31] Deng W-W, Ogita S, Ashihara H. Biosynthesis of theanine ( $\gamma$-ethylamino-L-glutamic acid) in seedlings of Camellia sinensis. Phytochem Lett 2008;1:115-9.

[32] Kennedy JF, Panesar PS, Eliasson AC, editors. Starch in food: structure, functions and applications, vol. 61. Cambridge, CB1 6AH, UK: Woodhead Publishing Ltd; 2004. p. 383-4. http://dx.doi.org/10.1016/j.carbpol.2005.05.006 (xiii 605 pp., £150.00, ISBN 0-85573-731-0). Carbohydrate Polymers 2005.

[33] LMC International (Oxford), European Commission. Directorate-general for agriculture and rural development. In: Evaluation of the community policy for starch and starch products: prepared for European commission - DG agriculture; 2002.

[34] O'Leary MH. Carbon isotopes in photosynthesis. Bioscience 1988;38:328-36. http://dx.doi.org/10.2307/1310735.

[35] Bateman AS, Kelly SD, Woolfe M. Nitrogen isotope composition of organically and conventionally grown crops. J Agric Food Chem 2007;55:2664-70.

[36] Camin F, Wietzerbin K, Cortes AB, Haberhauer G, Lees M, Versini G. Application of multielement stable isotope ratio analysis to the characterization of French, Italian, and Spanish cheeses. J Agric Food Chem 2004;52:6592-601.

[37] Howa JD, Lott MJ, Ehleringer JR. Isolation and stable nitrogen isotope analysis of ammonium ions in ammonium nitrate prills using sodium tetraphenylborate. Rapid Commun Mass Spectrom 2014;28:1530-4. 